\title{
Skilling Requirements in Textiles: Technical Training and Its Trainers-Sri Lanka in Perspective
}

\author{
Rohana U. Kuruppu ${ }^{1,2}$ \\ ${ }^{1}$ School of Fashion \& Textiles, RMIT University, Melbourne, Australia \\ ${ }^{2}$ Brandix College of Clothing Technology, Colombo, Sri Lanka \\ Email: rohanak@brandix.com
}

How to cite this paper: Kuruppu, R.U. (2018) Skilling Requirements in Textiles: Technical Training and Its Trainers-Sri Lanka in Perspective. Journal of Textile Science and Technology, 4, 101-116. https://doi.org/10.4236/jtst.2018.44007

Received: August 5, 2018

Accepted: November 11, 2018

Published: November 14, 2018

Copyright $\odot 2018$ by author and Scientific Research Publishing Inc. This work is licensed under the Creative Commons Attribution International License (CC BY 4.0).

http://creativecommons.org/licenses/by/4.0/

\begin{abstract}
The textile and clothing industry has become very competitive in the world over. There are many players in the industry. The most prominent player is China. Recent statistics reveal that China continue to be the world's largest textile and clothing producer in 2016 (Textiles outlook, 2017). China's major export markets are EU, USA and Japan. However, rising labour costs and production costs of China will shift production to lower cost suppliers. This will give South Asia and South-East Asia an opportunity to capitalize in their exports. The question is, can these regions in Asia take this challenge? To overcome the challenges, they must be ready with highly skilled manpower. The Tertiary and Vocational Educational Training system across Asian region must be geared to take this challenge of training the new recruits. Can these countries have adequate numbers of skilled, effective and experienced trainers to train the new recruits? Qualified trainers may be in short supply. Then, how quickly can these trainers be made available for training? Half-baked trainers would turn half-baked workers that will not give right condition to meet the future challenges. A recent study by the author has revealed that there are not enough qualified trainers to impart knowledge and skill for those in the textile and clothing industry in Sri Lanka. This can be the case across Asia. It is time that responsible professionals in the training industry should consider about trainers if they are to launch a massive skilling project to meet requirements of the textile/clothing industry. Skilling the trainers must be a priority. It will be interesting to note that there is a mismatch between trainees and training courses. Also, students are not attracted to training courses. So, there is a concern about who should be trained and are they available?
\end{abstract}




\section{Keywords}

Skilling, Competency, Training Requirement, Level of Understatement, Flexibility

\section{Introduction}

The textile and clothing industry has become very competitive in the global market. Will this competitiveness make changes in sourcing patterns of textiles and clothing in the world? In the year 2016 there were two important game changers in the world politics. These can have an impact on future patterns of textile sourcing [1]. The two changers were the Briton decided to leave the EU on $23^{\text {rd }}$ June 2016 and the US Presidential election on $8^{\text {th }}$ November 2016. These events can be important for the world textile industry because it can have some reflection on future trading arrangements, sourcing patterns and production locations. If these ideas were to take place in the future there will be opportunity elsewhere in the world. Looking at the export growth levels of textiles and clothing, there is a probability that South Asia and South-East Asia might demonstrate a significant production growth. It can be suggested that a textile and clothing hub might emerge in one of these regions in the future. The question is whether they are ready to take the challenge. To overcome the challenge, industries must be competitive. This is to say, there must be people who are highly skilled, innovative and intelligent who can drive our industries to better heights. Modern, newness, quick response, short lead times, high productivity, flexibility, lean management all will need to play in concert to drive this industry to be a global leader in the future. This will lead to a status of a modern manufacturing economy in the region. To achieve this high standard manufacturing, there must have excellent tertiary, higher educational and vocational learning environment to support the textile and clothing industry to move up the value chain and go beyond the staple products and associated production systems.

\subsection{Trends in the Textile and Clothing Industry}

The world's textile and clothing trade declined by $2.4 \%$ to US $\$ 726$ bn in 2016 following a $6.4 \%$ fall in the previous year [2]. The worldwide, declined textile and clothing trade was seen in most major trade flows, the main exception being intra-European trade. There had been a growth of 5\% in 2014 and $8.6 \%$ in 2013. The decline in trade in 2017 is primarily due to fall in exports to Europe. Another matter was the depreciation of the Euro against the dollar. The textile trade of the total textile and clothing trade remained at $39 \%$ whilst clothing trade share in the textile and clothing trade was at $61 \%$ in 2015 . The textile and clothing imports to USA had a 6.5\% drop in 2016. However, there was an improvement in 2017 by having $1.3 \%$ increase over 2016. This increase was not sufficient because it remained below the level of 2014 and 2015 [3]. EU textile and clothing 
imports rose in value by $1.6 \%$ to record high of US\$126.34 bn in 2017 following a $0.8 \%$ increase in 2016 . The world's largest textile exporter was China with a $37 \%$ share of world textile exports, followed by the EU, India, the USA, Turkey, South Korea, Taiwan, Hong Kong, Pakistan and Vietnam [2].

Tables 1-5 describes international trade in textiles/clothing in Asian region in 2015. Trade flows in textiles in Intra-Asian are promising than Intra-Asian trade flows in clothing. However, Intra-European trade flows in clothing in 2015 is much higher than textile trade flows to Intra-Europe.

Table 1. Percentage of the total textile/clothing trade in 2015.

$\begin{array}{ll}\text { Textile trade } & 39 \\ \text { Clothing trade } & 61\end{array}$

Table 2. Trade flows in textiles in 2015.

\begin{tabular}{cc}
\hline Worlds' textile trade flows & US\$ (billion) \\
\hline Intra-Asian textile trade & 88.00 \\
Intra-European textile trade & 55.9 \\
Asia to Europe & 27.2 \\
Asia to North America & 26.9 \\
\hline
\end{tabular}

Table 3. Trade flows in clothing in 2015.

\begin{tabular}{cc}
\hline Worlds' clothing trade flows & US\$ (billion) \\
\hline Intra-Asian clothing trade & 62.6 \\
Intra-European clothing trade & 105.6 \\
Asia to Europe in clothing & 82.3 \\
Asia to North America & 82.7 \\
\hline
\end{tabular}

Table 4. Asian Textile and clothing trade 2015 (US\$ billion).

\begin{tabular}{cc}
\hline Intra-Asian textile trade & 88.0 \\
Intra -Asian clothing trade & 62.6 \\
\hline
\end{tabular}

Ref. Textile intelligence, 2016. p. 80. No. 183.

Table 5. South-East Asia performance 2015.

\begin{tabular}{cc}
\hline Textile/clothing & Exports growth \% \\
Cambodia & +12.3 \\
Indonesia & -4.0 \\
Philippines & -21.9 \\
Thailand & -8.1 \\
Vietnam & +9.9 \\
\hline
\end{tabular}


Vietnam has a good growth in export sales to EU, USA and Japan. Their production in textiles and clothing within the country also had a remarkable growth during 2015 [4]. Their textile production growth was more than clothing production because they were expecting to take advantage of the preferential tariff benefits of the Trans-Pacific Partnership (TPP), when it is ratified. However, US pulled out of their involvement in the partnership, which means the agreement cannot be ratified and it is wait and see situation whether anything can be salvaged from this unexpected situation. Vietnam was to benefit from the TPP because the agreement would have given the clothing exporters of Vietnam duty free access to the markets of signatory countries in the TPP.

It is interesting to note that Vietnam had been the best performer among the top 10 suppliers of clothing to the US import market in 2016 [1]. Vietnam in value terms could increase by $7.0 \%$ and by volume $6.9 \%$ to the US import market in 2017. This is despite Vietnam being the $5^{\text {th }}$ highest price among the 10 largest suppliers. US imported from Vietnam at an average US $\$ 3.22$ per square metre equivalent (sme) whilst Cambodia exported to US at US $\$ 2.37$ per sme and was the third lowest among the ten largest suppliers [1] Still with these prices Cambodia could not hold on to their share of the market and ended with low volume and low-price situation. This means price is not the only matter in this world market.

From the foregoing paragraphs what could be the outcome? It clearly indicates that South Asia and South-East Asia are vibrant and competitive regions in the world for textile and clothing business. One must not forget there are other trade flows that can cause resistance to Asian trade flows in the future. However, it seems that world markets will be dominated by the Asian region soon. Therefore, human capital in the Asian regions must be capable of delivering textile and clothing at unprecedented level of expectations to their customers.

\subsection{Vocational Training-Skilling}

Many people in the world are engaged in some kind of vocation. Amongst the people engaged in vocational activities, a large majority of them are in blue collar or shop floor work environments. Just imagine, if all these people are heavily skilled and motivated what would be the outcome in terms of production and services? There will be many success stories in all sectors of the industry. The reason for success is people. How it became successful, it is their skill and motivation. How did that happen? Training provided the skill and motivation. So, it was a successful training. Training became successful due to many reasons but amongst them trainer's contribution is significant. We need a driver, converter, and some transform mechanism to shift people to new ways of doing work, think differently and bring about results. All these are possible only with trainers who can deliver a change in people for better. Therefore, a trainer is an important asset and their contribution is essential to enhance the productivity in textile/clothing enterprises. 
Training the people who are already engaged in production will bring immediate results. To change the habits of people already in the industry need careful consideration. To impart skills to such people you need not only have the skill of the subject concerned but also the skill to drive the essence of skill into their minds that will make them understand and implement successfully and comfortably. People in the industry show resistance to training unlike school leavers who are eager to learn. Therefore, you need a special skill to train those already engaged at work.

A trainer must be accomplished with many facets of skills. The industry must recognize his/her work. There is a need to develop a relationship between the industry and training fraternity. Trainers need to understand the industry needs and cater to those requirements. Industry must provide opportunity for trainers to participate in the industry. More interactions they have better equipped they are when imparting skills to employees. Therefore, it is necessary for trainers to become part and parcel of the industry and more particularly in the area of their specialty and acquire skills from the industry.

In the context of training, the first and foremost is that the trainer must have acquired thorough knowledge and skill about the macro area of training e.g. textile technology. The second is hands on experience in that field of training e.g. spinning. These two together makes one to qualify to enter the training profession. This becomes the basic entry specification for teachers/trainers. This is not to be seen amongst most trainers.

\section{Method}

The purpose of this is to know how well trainers perform in training. Let us see what entry qualifications trainers do require to be trainers. In this case, better to know their knowledge about the subject/industry and industry exposure. These two are of prime importance to a trainer. Attempts will be taken to know the understanding of the subject by the students, whether trainers are trained and matching the trainees needs with the training course. All these together, it will be able to judge how successful is the training industry.

\subsection{Sample}

Large five training institutions were identified for the experiment. Out of which two were Universities, one government owned training centre, and two private training centres. All these centres are recognized training centres by the industry. They were marked as Uni.1, Uni.2, GTI, PT1 and PT2 respectively. Uni.1 and 2 both have courses leading to textiles and clothing and GTI is dedicated for middle management and technical skills and for sewing machine maintenance. The two privately owned training centres too have courses leading to clothing studies.

\subsection{Panel}

The entry level requirements for trainers stipulated by the three-member panel 
from the industry. They had specialized knowledge and hands-on experience. The panel identified the requirements for knowledge and capability of each trainer. The capability indicates the ability to conduct training.

\subsection{Experiments}

1) Minimum criteria for trainers

Following was the criteria adopted to assess the minimum requirement to become a trainer. The first experiment was to know the entry requirements for a trainer.

Table 6 is the requirement criteria proposed by the panel for assessment of knowledge and capability of trainers. They were evaluated in two segments, i.e. Knowledge-followed a systematic course; and minimum industry exposure.

According to this criterion (Table 6), a new graduate can have 35 marks ( $25+$ 10). A just graduated Diplomate can have 25 marks $(15+10)$ provided $s /$ he had one-year industry experience. The requirement to become a trainer is 35 marks. Therefore, a Diplomate may have to have additional 10 marks which can acquire by doing two short courses. If you have done only a short course, then you get 5 marks. Along with the short course the candidate has done six months industry training then additional 5 marks, altogether 10 marks. A trainer of this qualifications need to add 25 marks which can come from industry experience. Therefore, a such trainer needs to have 5 years of industry experience.

Following are the other requirements for a successful training. That is, level of understanding, training the trainer for technical trainers, and matching training needs. It is also necessary to know what the training needs are when designing a training course.

2) Level of understanding

The next experiment was to find out the understanding of what was taught to students. In this case four subjects were identified at random and carried out interviews with students to know the level of understanding of the subjects. This helped to know how successful the delivery was.

3) Specific teacher training

The third was to ascertain whether the trainer has undergone any specific teacher training or modern teaching methods to train students. This was done by speaking to the authorities of individual institutions.

4) Match trainees need with the training

Table 6. Entry requirement criteria for trainers.

\begin{tabular}{ccccccc}
\hline variable & degree & diploma & Short courses & seminars & research & minimum \\
\hline knowledge & 25.0 & 15.0 & 5.0 & 2.5 & 2.5 & 25.0 \\
$\begin{array}{c}\text { Industry } \\
\text { Exposure }\end{array}$ & $\begin{array}{c}\text { In-plant train } \\
(1 \mathrm{Yr})\end{array}$ & $\begin{array}{c}\text { In-plant train } \\
(1 \mathrm{yr})\end{array}$ & $\begin{array}{c}\text { In-plant } \\
6 \text { months }\end{array}$ & $\begin{array}{c}\text { Post train } \\
(1 \mathrm{yr})\end{array}$ & $\begin{array}{c}\text { Post train } \\
(2 \mathrm{yrs})\end{array}$ & minimum \\
Marks for industry & 10.0 & 10.0 & 5.0 & 5.0 & 20.0 & 30.0 \\
\hline
\end{tabular}


The next was to know whether these institutions match trainees' needs with the training course. Again, institution authorities were asked whether they matched trainees to training courses.

5) Training needs analysis

A study was carried out to know whether training institutions carryout training needs analysis of the textile/clothing industry.

\section{Results}

1) Minimum criteria for trainers

Entry level requirements for trainers were evaluated. The trainers were selected at random in the basis of 3 per institution. Altogether 15 of them were evaluated and following are the results.

a) Knowledge criterion

Considering Tables 7-11 in the basis of knowledge, it seems that trainers have got necessary entry requirements to be a trainer as per criteria stipulated by the panel. In these tables the degree means the period of education and in the case of degree it is minimum of four years fulltime study which include one year of industry experience. Whilst diploma means full time study of two years plus one-year industry exposure. Short courses are technical courses on a specific subject for a short period and seminar means attending series of lectures of different subjects.

Table 7. Assessment of the trainers in University 1.

\begin{tabular}{ccccccc}
\hline Uni.1 & degree & diploma & Short courses & seminar & research & Total \\
\hline Trainer 1 & 25.0 & 00.0 & 05.0 & 02.5 & 02.5 & 35.0 \\
Trainer 2 & 25.0 & 00.0 & 00.0 & 02.5 & 02.5 & 30.0 \\
Trainer 3 & 25.0 & 00.0 & 05.0 & 02.5 & 02.5 .0 & 35.0 \\
Average & 25.0 & 00.0 & 03.5 & 02.5 & 02.5 & 33.3 \\
\hline
\end{tabular}

Source: experimental data.

Table 8. Assessment of the trainers in University 2.

\begin{tabular}{ccccccc}
\hline Uni.2 & degree & diploma & Short courses & seminar & research & Total \\
\hline Trainer 1 & 25.0 & 00.0 & 00.0 & 02.5 & 02.5 & 30.0 \\
Trainer 2 & 25.0 & 00.0 & 00.0 & 00.0 & 00.0 & 25.0 \\
Trainer 3 & 25.0 & 15.0 & 00.0 & 00.0 & 00.0 & 40.0 \\
Average & 25.0 & 15.0 & 00.0 & 00.8 & 00.8 & 31.6 \\
\hline
\end{tabular}

Source: experimental data.

Table 9. Assessment of the trainers in government training institute (GTI).

\begin{tabular}{ccccccc}
\hline GTI & degree & diploma & Short courses & seminar & research & Total \\
\hline Trainer 1 & 00.0 & 15.0 & 05.0 & 00.0 & 00.0 & 20.0 \\
Trainer 2 & 25.0 & 00.0 & 05.0 & 00.0 & 00.0 & 30.0 \\
Trainer 3 & 25.0 & 00.0 & 05.0 & 02.5 & 00.0 & 32.5 \\
Average & 16.6 & 05.0 & 05.0 & 00.8 & 00.0 & 28.1 \\
\hline
\end{tabular}

Source: experimental data. 
Table 10. Assessment of the trainers in private training institute (PT1).

\begin{tabular}{ccccccc}
\hline PT1 & degree & diploma & Short courses & seminar & research & Total \\
\hline Trainer 1 & 25.0 & 15.0 & 05.0 & 02.50 & 00.0 & 47.5 \\
Trainer 2 & 25.0 & 00.0 & 05.0 & 00.0 & 00.0 & 30.0 \\
Trainer 3 & 25.0 & 00.0 & 00.0 & 02.5 & 00.0 & 27.5 \\
Average & 25.0 & 05.0 & 03.3 & 01.6 & 00.0 & 35.0 \\
\hline
\end{tabular}

Source: experimental data.

Table 11. Assessment of the trainers in private training institute (PT2).

\begin{tabular}{ccccccc}
\hline PT2 & degree & diploma & Short courses & seminar & research & Total \\
\hline Trainer 1 & 25.0 & 00.0 & 00.0 & 02.50 & 02.5 & 30.0 \\
Trainer 2 & 25.0 & 00.0 & 00.0 & 00.0 & 00.0 & 25.0 \\
Trainer 3 & 00.0 & 15.0 & 05.0 & 00.0 & 00.0 & 20.0 \\
Average & 16.6 & 05.0 & 01.6 & 00.8 & 00.8 & 25.0 \\
\hline
\end{tabular}

Source: experimental data.

b) Industry Exposure

The results in Tables 12-16 indicate that trainers have the industry exposure to be a qualified trainer. Since, they had the necessary knowledge criterion as well (Tables 7-11), they have the minimum requirement to be a trainer.

2) Level of understanding

The successfulness of the delivery was evaluated. Carefully four subjects were selected where there is no much variation within the four subjects. For example, production management oriented subjects were selected.

A questionnaire was developed and distributed among the second year-students and their answers were tabulated to a final score for understanding. The questionnaire was broken into three parts; preparatory and introduction; the delivery and conclusion with tutorial. The questionnaire was administered to 12 people (4 per institution). Three institutions were targeted.

Table 17, explains the understanding of the lectures by the students. As explained, each lecture was broken into three sections, preparatory, delivery and tutorial. Each of these sections had questions and students had the opportunity to express their views. Their answerers were marked 1, 2 or 3 as 1 being agree, 2 as not agree and 3 do not know. The questionnaire is given in the appendix 1 . The questionnaire was administered by the author and there was no attempt to understand his point of view of the lectures concerned. Attempt was only to understand students point of view.

Whilst previous test evaluated the understanding the lecture and now the lecture was rated, as clearly explained, supplemented by hand outs and interesting; and a good lecture. Each of these sections were marked out of 15, 15 and 20 respectively and final score was interpreted out of 100 . This test was subjected to two institutions (GT1 \& PT1) and 4 students per institution were taken for the test. The results are in Table 18. 
Table 12. Assessment of the trainers in University 1.

\begin{tabular}{ccccccc}
\hline Uni. 1 & In-plant $(1$ yr) & In-plant $(1$ yr $)$ & In-plant $(6 \mathrm{~m})$ & Post train $(1 \mathrm{yr})$ & Post train $(2 \mathrm{yr})$ & Total \\
\hline Trainer 1 & 10.0 & 00.0 & 00.0 & 05.0 & 00.0 & 15.0 \\
Trainer 2 & 10.0 & 00.0 & 00.0 & 05.0 & 00.0 & 15.0 \\
Trainer 3 & 10.0 & 00.0 & 00.0 & 00.0 & 20.0 & 30.0 \\
Average & 10.0 & 00.0 & 00.0 & 03.3 & 06.6 & 20.0 \\
\hline
\end{tabular}

Source: experimental data.

Table 13. Assessment of the trainers in University 2.

\begin{tabular}{ccccccc}
\hline Uni.2 & In-plant $(1 \mathrm{yr})$ & In-plant $(1 \mathrm{yr})$ In-plant $(6 \mathrm{~m})$ & Post train $(1 \mathrm{yr})$ & Post train $(2 \mathrm{yr})$ & Total \\
\hline Trainer 1 & 10.0 & 00.0 & 00.0 & 05.0 & 00.0 & 15.0 \\
Trainer 2 & 10.0 & 00.0 & 00.0 & 05.0 & 00.0 & 15.0 \\
Trainer 3 & 10.0 & 00.0 & 05.0 & 00.0 & 20.0 & 35.0 \\
Average & 10.0 & 00.0 & 01.6 & 03.3 & 06.6 & 21.6 \\
\hline
\end{tabular}

Source: experimental data.

Table 14. Assessment of the trainers in government training institute (GTI).

\begin{tabular}{ccccccc}
\hline GTI & In-plant $(1 \mathrm{yr})$ & In-plant $(1 \mathrm{yr})$ & In-plant $(6 \mathrm{~m})$ & Post train $(1 \mathrm{yr})$ & Post train $(2 \mathrm{yr})$ & Total \\
\hline Trainer 1 & 00.0 & 10.0 & 00.0 & 00.0 & 20.0 & 15.0 \\
Trainer 2 & 10.0 & 00.0 & 00.0 & 05.0 & 00.0 & 15.0 \\
Trainer 3 & 10.0 & 00.0 & 00.0 & 00.0 & 20.0 & 30.0 \\
Average & 06.6 & 03.3 & 00.0 & 01.6 & 13.3 & 25.0 \\
\hline
\end{tabular}

Source: experimental data.

Table 15. Assessment of the trainers in private training institute (PT1).

\begin{tabular}{|c|c|c|c|c|c|c|}
\hline PT1 & In-plant (1 yr) & In-plant (1 yr) & In-plant $(6 \mathrm{~m})$ & Post train (1 yr) & Post train (2 yr) & Total \\
\hline Trainer 1 & 10.0 & 00.0 & 00.0 & 00.0 & 20.0 & 30.0 \\
\hline Trainer 2 & 00.0 & 00.0 & 05.0 & 00.0 & 20.0 & 25.0 \\
\hline Trainer 3 & 00.0 & 00.0 & 05.0 & 00.0 & 20.0 & 25.0 \\
\hline Average & 03.3 & 00.0 & 03.3 & 00.0 & 20.0 & 26.6 \\
\hline
\end{tabular}

Source: experimental data.

Table 16. Assessment of the trainers in private training institute (PT2).

\begin{tabular}{|c|c|c|c|c|c|c|}
\hline PT2 & In-plant (1 yr) & In-plant (1 yr) & In-plant $(6 \mathrm{~m})$ & Post train (1 yr) & Post train (2 yr) & Total \\
\hline Trainer 1 & 10.0 & 00.0 & 00.0 & 05.0 & 00.0 & 15.0 \\
\hline Trainer 2 & 10.0 & 00.0 & 00.0 & 00.0 & 20.0 & 30.0 \\
\hline Trainer 3 & 00.0 & 10.0 & 00.0 & 00.0 & 20.0 & 30.0 \\
\hline Average & 06.6 & 03.3 & 00.0 & 01.3 & 13.3 & 25.0 \\
\hline
\end{tabular}

Source: experimental data. 
Table 17. Results of the questionnaire of understanding the delivery.

\begin{tabular}{|c|c|c|c|c|c|c|c|c|c|c|c|c|c|c|c|c|c|}
\hline \multirow{2}{*}{ Student } & \multicolumn{5}{|c|}{ Preparatory } & \multicolumn{6}{|c|}{ Delivery } & \multicolumn{5}{|c|}{ Tutorial } & \multirow{2}{*}{$\%$} \\
\hline & 1 & 2 & 3 & 4 & 5 & 1 & 2 & 3 & 4 & 5 & 6 & 1 & 2 & 3 & 4 & 5 & \\
\hline 1 Uni 1 & 3 & 2 & 1 & 3 & 1 & 1 & 1 & 1 & 2 & 2 & 2 & 2 & 2 & 2 & 2 & 2 & 31 \\
\hline 2 & 2 & 3 & 1 & 2 & 1 & 1 & 1 & 1 & 2 & 2 & 2 & 3 & 2 & 3 & 2 & 2 & 31 \\
\hline 3 & 3 & 2 & 1 & 2 & 1 & 1 & 1 & 1 & 2 & 2 & 2 & 3 & 3 & 2 & 2 & 2 & 38 \\
\hline 4 & 2 & 2 & 2 & 2 & 3 & 1 & 1 & 1 & 3 & 2 & 2 & 3 & 2 & 2 & 2 & 2 & 31 \\
\hline 1 Uni 2 & 1 & 3 & 1 & 3 & 1 & 2 & 1 & 1 & 1 & 1 & 2 & 1 & 2 & 2 & 2 & 2 & 50 \\
\hline 2 & 1 & 2 & 1 & 3 & 1 & 2 & 1 & 3 & 1 & 1 & 2 & 3 & 3 & 2 & 1 & 3 & 69 \\
\hline 3 & 1 & 1 & 3 & 3 & 1 & 1 & 1 & 1 & 2 & 2 & 2 & 2 & 3 & 2 & 2 & 2 & 44 \\
\hline 4 & 2 & 2 & 3 & 3 & 1 & 1 & 1 & 2 & 2 & 2 & 2 & 2 & 3 & 2 & 2 & 2 & 25 \\
\hline $1 \mathrm{~T}(\mathrm{P}) 1$ & 1 & 3 & 1 & 2 & 1 & 1 & 1 & 1 & 2 & 1 & 2 & 2 & 2 & 2 & 3 & 1 & 56 \\
\hline 2 & 1 & 3 & 1 & 2 & 1 & 1 & 2 & 1 & 2 & 2 & 2 & 2 & 2 & 3 & 3 & 2 & 44 \\
\hline 3 & 1 & 2 & 2 & 2 & 2 & 1 & 1 & 1 & 2 & 1 & 2 & 2 & 2 & 2 & 2 & 3 & 38 \\
\hline 4 & 1 & 3 & 1 & 2 & 1 & 1 & 1 & 2 & 2 & 3 & 2 & 2 & 2 & 2 & 2 & 3 & 44 \\
\hline
\end{tabular}

Source: experimental data. Note: 1-Agree; 2-Not Agree; 3-Do Not Know.

Table 18. Rating the lecture by the students.

\begin{tabular}{cccccccccccccccccc}
\hline Students & \multicolumn{3}{c}{ Subject 1 } & \multicolumn{4}{c}{ Subject 2 } & \multicolumn{4}{c}{ Subject 3 } & \multicolumn{5}{c}{ Subject 4} \\
\hline GT1 & $15 \%$ & $15 \%$ & $20 \%$ & $\mathrm{~T}$ & $15 \%$ & $15 \%$ & $20 \%$ & $\mathrm{~T}$ & $15 \%$ & $15 \%$ & $20 \%$ & $\mathrm{~T}$ & $15 \%$ & $15 \%$ & $20 \%$ & $\mathrm{~T}$ \\
\hline 1 & 5 & 15 & 5 & 25 & 2 & 8 & 5 & 15 & 5 & 10 & 5 & 20 & 6 & 10 & 8 & 24 \\
2 & 6 & 10 & 5 & 21 & 4 & 8 & 4 & 16 & 4 & 10 & 5 & 19 & 5 & 10 & 10 & 25 \\
3 & 4 & 8 & 5 & 17 & 5 & 7 & 4 & 16 & 5 & 8 & 6 & 19 & 4 & 8 & 4 & 12 \\
4 & 3 & 5 & 5 & 13 & 7 & 7 & 5 & 19 & 4 & 6 & 5 & 15 & 4 & 5 & 5 & 14 \\
\hline & & & & & & & & & & & & & & & \\
\hline Students & & Subject 1 & & & Subject 2 & & & Subject 3 & & & Subject 4 & \\
\hline PT1 & $15 \%$ & $15 \%$ & $20 \%$ & $\mathrm{~T}$ & $15 \%$ & $15 \%$ & $20 \%$ & $\mathrm{~T}$ & $15 \%$ & $15 \%$ & $20 \%$ & $\mathrm{~T}$ & $15 \%$ & $15 \%$ & $20 \%$ & $\mathrm{~T}$ \\
\hline 1 & 5 & 10 & 5 & 15 & 2 & 6 & 5 & 13 & 5 & 11 & 7 & 23 & 6 & 7 & 8 & 21 \\
2 & 6 & 11 & 4 & 21 & 4 & 5 & 4 & 13 & 4 & $8 \mathrm{~h}$ & 5 & 17 & 5 & 7 & 9 & 21 \\
3 & 5 & 8 & 6 & 19 & 6 & 6 & 7 & 19 & 6 & 9 & 6 & 21 & 5 & 7 & 5 & 17 \\
4 & 4 & 7 & 5 & 16 & 8 & 6 & 8 & 22 & 4 & 7 & 8 & 19 & 5 & 7 & 8 & 20 \\
\hline
\end{tabular}

$\mathrm{T}-\mathrm{is}$ the total of the percentages.

Rating the lecture is also part of the understanding the lecture. Both these tests (Table 17 and Table 18) would indicate the level of understanding the lecture/delivery.

\section{3) Specific teacher training}

This is the third evaluation to know whether the trainers have been trained to deliver technical skills. Do they know how to impart skills? A survey was carried out in this regard. Interviews were held with trainers. Except for very few, most 
of them have had no such training. It is believed that there is no such culture in Sri Lankan textile training industry.

4) Match trainees need with training

A study was conducted to understand this aspect of requirement. It was revealed that the government training centre and the two private training centres do carryout a trainability test to know the suitability of trainees. Trainees need to learn is also checked. The universities too have method of matching but not very comprehensive like others.

Further, trainees too have their requirements to learn. Especially, those who are working in the industry. Trainees reveal that their needs are not met more often by the training counterparts.

5) Training needs analysis

Training needs of the industry is a prime requirement to understand the type of training that should be imparted to the employees. Except one training institution in the list the rest do not practice regularly (interview) the training needs of the industry. Most of them do carryout consultative committee meetings with the industry. However, there is no evidence to record that there is any serious attempt to understand the industry needs. Without knowing what the industry wants there is no purpose of training. Sharing knowledge between training institution and the industry is not freely happening.

\section{Data Analysis (Summary)}

Table 19 indicates the average level of marks taken by trainers as per institution in terms of entry requirements to become a trainer. As such, Table 19, shows that PT 1 has the best qualified trainers among the other trainers. However, the rest are comparatively similar to each other.

Table 6, shows a new graduate can score without working in the industry 35 . This amount is the minimum requirement to enter the training industry. However, for a new diplomate would need to add few short courses or so to get to 35 . Under this criterion all of them qualify to be trainers. How have they responded to good training, good delivery etc. according to student point of view? This was measured by the student understanding. Except three students (Table 20) others have marked as poor understanding of lectures. Students have rated the lectures (Table 21) also low. Overall, the delivery has been poor.

Table 19. Final score of the entry level requirement for trainers.

\begin{tabular}{cccc}
\hline Institutions & Knowledge & Industry exposure & Total \\
\hline Uni 1 & 33.3 & 20.0 & 53.3 \\
Uni 2 & 31.6 & 21.6 & 53.2 \\
GTI & 28.1 & 25.0 & 53.1 \\
PT1 & 35.0 & 26.6 & 61.6 \\
PT2 & 25.0 & 25.0 & 50.0 \\
\hline
\end{tabular}

Source: experimental data. 
Table 20. Students understanding of the deliveries (\%).

\begin{tabular}{cccc}
\hline Students & Uni. 1 & Uni. 2 & T (P) 1 \\
\hline 1 & 31 & 50 & 56 \\
2 & 31 & 69 & 44 \\
3 & 38 & 44 & 38 \\
4 & 31 & 25 & 44 \\
Average & 32.8 & 47 & 45.5 \\
\hline
\end{tabular}

Source: experimental data.

Table 21. Rating the lecture by the students (\%).

\begin{tabular}{ccccc}
\hline Students & Subject 1 & Subject 2 & Subject 3 & Subject 4 \\
\hline 1 (GT 1) & 50 & 30 & 40 & 48 \\
2 & 42 & 32 & 38 & 50 \\
3 & 34 & 32 & 38 & 24 \\
4 & 26 & 38 & 30 & 28 \\
1 PT 1 & 30 & 26 & 46 & 42 \\
2 & 42 & 26 & 34 & 42 \\
3 & 38 & 38 & 42 & 34 \\
4 & 32 & 44 & 38 & 40 \\
\hline
\end{tabular}

Source: experimental data.

\section{Discussion}

Five well established skilling institutions were taken in to the study. First, they studied whether they conform to the criterion when selecting teachers/trainers. When contacted the students to find out about the understanding of practical aspects of the subject, it was revealed that only $50 \%$ of them could understand what was being imparted. Students have not rated the lectures as good. This reflects bad upon teachers/trainers. This happens due to lack of industry experience in the lecturers. The third requirement is, training to become a technical teacher or trainer. There is no practice to conduct training to become a technical trainer. This is not common in Sri Lanka. There is no requirement as such specified by any authority in Sri Lanka. Technical trainers are self-made. They have not undergone any specific training as to how one should impart technical aspects to a trainee. However, there is "Teacher Training" but not for technical trainers as to how they should impart training. This must be made compulsory to technical teachers/trainers. Training the trainer module can be time consuming. As such, to produce a qualified technical teacher/trainer is not something one could do quickly. In the absence of these skills students are finding difficult to understand the trainers. The effort put in by the trainers is of no use. Table 17 reveals there is poor understanding of the subject and study has revealed that there is no evidence of teacher training for technical trainers. 
The way the textile and clothing industry of Asian region is expected to move forward in the future, there will be an enormous need for skills and knowledge to take the industry to a better height and make the Asian region, the hub for textiles and clothing. The Asian region's human capital is an essential resource and capable of achieving the goals and transforming the economy into a modern manufacturing area. In this context, it is necessary to be equipped with modern teaching methods which in turn will produce a learned workforce with market oriented skills. The training industry will have to produce skilled workforce to all levels of job categories to compete globally.

Whilst there is a concern with the skills of the trainers, there is also a concern about trainees. Identifying people with right attitude and perfect mind-set for learning is hard to find. Therefore, some will not grasp skills. A few will not match to the expectations. When the person's training needs does not match with the training course, it is a mismatch. It is necessary to match this as far as possible but it can be a difficult task. These are some of the reasons where training is not always successful. To overcome this hurdle some institutions carryout a trainability test on the candidates.

The estimated world population growth of 9.3 billion by 2050 , will have profound impact on the future demand for manufactured goods and this will have implications for skills requirements [5]. The training requirement for the Asian region for the future, can be huge. Although there are enough and more people available for work, it can be a daunting task to enroll people for training. In Sri Lanka only $3 \%$ of the people in the age group of 20 to 24 enrolled for technical education and vocational training (TEVT) in 2014 [6]. One reason for this as mentioned in the World Bank's world development indicators report is under developed TEVT in Sri Lanka. Jayawardena [6] in her study reveals that nearly 130,000 school dropouts every year find unskilled or casual jobs, is because either they are not interested in training or no suitable training course for them (mismatch). Some fail the selection test. Just about $10 \%$ of the age 20 and above are having competency certificates relevant to their jobs in Sri Lanka [6]. It seems not only trainers are in short supply but also the trainees for courses. This is something like add insult to injury, on one side there are no trainees for training and from the other trainees are being sent out due to mismatch. The influx of people are not necessarily the ones that training industry is looking out to train. Trainees also need to qualify for a training course. There is another group of people who are not employable before and after having received the training. National Employability report of 2014 of India states that only $18.6 \%$ are employable graduates out of six hundred thousand software engineers. Here, there is no employability in the training. After all, training must lead to prosperity and employability. This is a complicated situation. As such, there is a need to plan for the future. Training industry will need to play a close role alongside with the textile/clothing industries to make a successful launch for better future for them all. 
Lack of trainers is a prime concern and it is a problem in all aspects of training and learning industry. The issue is in the delivery because the trainer is not skilled to impart knowledge due to little or no experience in the specific field as well as method of delivery. It has been said that trainers have not being trained to train. Ineffective trainers drive away the trainees thus less people in the training course. Further, it brings bad taste to the institution which in turn, not many would patronize.

The next is not enough trainees in the course. There are two aspects to it. Those who wish to learn probably do not find relevant training courses available in the country. The training courses do not match the need of the trainee. There is a mismatch between the trainee and the training course. This is to say a person who would like to become a skilled mechanic would not like to follow a pattern making course and become a pattern maker. The demand for the course is proportional to employability and interest to that particular profession. Therefore, employability and one's interest go hand in hand to match a training course. At the end of the training, the candidate must benefit from it.

The other reason for not patronizing the courses is lack of interest in learning. This aspect has been highlighted even in India that students do not attach much value to training [7]. This is a challenge, most training providers face. There are many in this category. They must be attracted to training. Incentives have been given in the past but have not been very successful. Something new, yet very exciting for the youth will draw their attention. Just imagine, India has 600 million people currently, in the age group of 15 to 59 and if this population can make a significant contribution to the country's growth, provided they are equipped to be productive [7].

\section{Outcome}

The findings of this work reveal that performance levels of trainers are not satisfactory. Most of the trainers do not have experience in the industry. There is no effort taken to improve their performance because there is no training the trainer programmes for those who impart technical training in Sri Lanka. Training institutions do not practice training needs analysis of the industry. There is a gap between the training and the industry. This has resulted no or few nominations from the industry for training courses. Further the trainees are also wanting to improve their knowledge and skill. Trainees reveal that their interests are not met. It means that there are no training courses to improve their skills. The training industry will need to revamp their strategies and meet the requirements of the industry and trainees as well.

\section{Conclusions}

The textile and clothing industry is active and vibrant in the Asian region. Textile and clothing trade flows from Asia are dominating than others. That means business is taking place in the Asian region. There is a possibility of a textile and 
clothing hub to emerge in Asia. As a result of these emerging trends Asian enterprises must be geared to deliver innovative, modern and competitive textile and clothing products to their western customers.

To meet these challenges the human resources must be ready to provide whatever the product that is in demand quickly, perfectly and competitively. To perform this activity, the industry would need highly skilled workforce. In the effort to make the workforce effective and productive, the textile and clothing industry might have to depend on training industry. At this point, it is rather disappointing to understand the unsatisfactory delivery of training. Trainers have failed to demonstrate effective training and impart skills to trainees. Lack of good, qualified and results oriented trainers in the industry is a major drawback. This aspect must be considered as important.

Further, to find right type of trainees for training courses is also a concern. Finally, those who are not interested in learning must be motivated to take up a relevant and suitable training course and that can be a worthwhile effort. While skilling people, empowering them to build upon their capabilities for jobs and fine tuning their entrepreneurial skills all that pave the way to building a skilled and powerful nation [8].

\section{Conflicts of Interest}

The authors declare no conflicts of interest regarding the publication of this paper.

\section{References}

[1] Anson, R. (2017) Editorial. Textile Outlook International. No. 184. Textile Intelligence, UK.

[2] Textile Outlook International (2017) No.189. Textiles Intelligence, UK, 77.

[3] Textile Outlook International (2018) No 190. Textiles Intelligence, UK.

[4] Textile Outlook International (2016) No.183. Textile Intelligence, UK, 73.

[5] Future Skills Needs (2013) Future Skills Requirements of the Manufacturing. Future Skills Needs. Ireland.

[6] Jayawardena, P. (2017) Bridging the Skill Gap. Ceylon Daily News. Lake House, Colombo.

[7] Raman, K. (2016) Skilling India: Opportunities \& Imperatives for the Private Sector. Tata Strategic Mgt. Group. Mumbai. India.

[8] India Skills (2016) Wheebox. Confederation of Indian Industry. 


\section{Appendix 1}

\section{A Questionnaire}

Objective: To know the understanding of the lecture/delivery

Preparatory

1) Tutor looked relax and ready to deliver. Yes/No

2) Tutor was ready/organized to deliver. Yes/No

3) Tutor provided an introduction to the current delivery. Yes/ No

4) Tutor asked questions relating to the subject? Yes/No

5) Tutor always kept the class at ease. Yes/No

Delivery

1) Tutor was speaking well but not looking at the students whilst delivery. Yes/No

2) Tutor was speaking too fast. Yes/No

3) Tutor did not give adequate examples to understand more fully. Yes/ No

4) It was a very interesting delivery. Yes/No

5) Tutor interacted with students. Yes/No

6) Tutor was concern about the weak students. Yes/No

Tutorial

1) It was possible to think the ending the delivery was good. Yes/No

2) Tutor discussed the key points once again. Yes/No

3) Tutor gave a few questions for the students to think. Yes/No

4) Students felt it was a good delivery. Yes/No

5) Tutor made concluding remarks and emphasized on key issues at the end of the delivery. Yes/No 